\title{
The Influence of Direct and Indirect Speech on Source Memory
}

\author{
Anita Eerland* and Rolf A. Zwaan ${ }^{\dagger}$
}

People perceive the same situation described in direct speech (e.g., John said, "I like the food at this restaurant") as more vivid and perceptually engaging than described in indirect speech (e.g., John said that he likes the food at the restaurant). So, if direct speech enhances the perception of vividness relative to indirect speech, what are the effects of using indirect speech? In four experiments, we examined whether the use of direct and indirect speech influences the comprehender's memory for the identity of the speaker. Participants read a direct or an indirect speech version of a story and then addressed statements to one of the four protagonists of the story in a memory task. We found better source memory at the level of protagonist gender after indirect than direct speech (Exp. 1-3). When the story was rewritten to make the protagonists more distinctive, we also found an effect of speech type on source memory at the level of the individual, with better memory after indirect than direct speech (Exp. 3-4). Memory for the content of the story, however, was not influenced by speech type (Exp. 4). While previous research showed that direct speech may enhance memory for how something was said, we conclude that indirect speech enhances memory for who said what.

Keywords: speech type; source memory; situation models; discourse processing; language comprehension

Consider the following excerpt of a conversation:

"My dear Mr. Bennett," said his lady to him one day,
"have you heard that Netherfield Park is let at last?"
Mr. Bennett replied that he had not.
"But it is," returned she; "for Mrs. Long has just
been here and she told me all about it."
Mr. Bennett made no answer.
"Do not you want to know who has taken it?" cried
his wife impatiently.
"You want to tell me and I have no objection to
hearing it."
This was invitation enough.
"Why, my dear, you must know, Mrs. Long says
that Netherfield is taken by a young man of large
fortune from the north of England; that he came
down on Monday in a chaise and four to see the
place, and was so much delighted with it, that he
agreed with Mr. Morris immediately; that he is to
take possession before Michaelmas, and some of

* Department of Languages, Literature, and Communication, Utrecht University, Utrecht, NL

+ Department of Psychology, Education, and Child Sciences, Erasmus University Rotterdam, Rotterdam, NL

Corresponding author: Anita Eerland (anita.eerland@gmail.com) his servants are to be in the house by the end of next week."

"What is his name?"

"Bingley."

"Is he married or single?"

"Oh! Single, my dear, to be sure! A single man of large fortune; four or five thousand a-year. What a fine thing for our girls!"

(Pride and Prejudice, Jane Austen, 1813)

This excerpt reveals several aspects of a situation that a comprehender might mentally represent. The comprehender may represent what was said, either the gist (i.e., general meaning) of what was said or perhaps even the exact wording of an utterance. But the comprehender could also have a stronger mental representation of who said what. The first could be called a mental representation of the meaning and the surface structure (i.e., linguistic characteristics) and the second one of the information source. In this article, we hypothesize that the use of direct versus indirect speech shifts the emphasis from one type of representation to the other. For example, direct speech, in which a protagonist is quoted directly (e.g., "My dear Mr. Bennett," said his lady to him one day, "have you heard that Netherfield Park is let at last?") may shift the emphasis toward the exact wording of an utterance, whereas indirect speech (e.g., Mr. Bennett replied that he had not.) may shift the emphasis toward the identity 
of the speaker. As we will discuss below, there already is evidence for the former hypothesis. The latter hypothesis is the focus of this article.

Understanding discourse involves forming a mental representation of the described situation, a situation model (e.g., Bransford, Barclay, \& Franks, 1972; JohnsonLaird, 1983; Morrow, Greenspan, \& Bower, 1987; Van Dijk \& Kintsch, 1983; Zwaan \& Radvansky, 1998). Situation models are integrations of information provided by the discourse with the comprehender's background knowledge. Linguistic cues can have subtle effects on the content of situation models and thus on the way we think about a described situation (e.g., Ferretti, Kutas, McRae, 2007; Huette, Winter, Matlock, Ardell, \& Spivey, 2014; Kaup, 2001; Kaup \& Zwaan, 2003; Lüdtke, Friedrich, De Filippis, \& Kaup, 2008; Madden \& Zwaan, 2003; Magliano \& Schleich, 2000; Sherrill, Eerland, Zwaan, \& Magliano, 2015). One such linguistic cue is speech type, which is the focus of the current study. More specifically, this study examines the impact of using direct vs. indirect speech on the comprehender's mental representation.

The fact that we encounter and use both direct and indirect speech in everyday spoken and written language suggests that these speech types serve different functions. What are these differences? Linguistic and psychological research have suggested several answers. One important difference is the way direct and indirect speech are perceived. Indirect speech is considered to be description-like, whereas direct speech is thought to be more depiction-like (Clark, 2016; Clark \& Gerrig, 1990). This leads to the assumption that indirect speech focuses on the gist of a particular message whereas direct speech focuses on its literal wording (it matters how something was said). This assumption is supported by evidence that comprehenders have better verbatim memory of a previously read sentence when direct rather than indirect speech was used (Bohan, Sanford, Cochrane, \& Sanford, 2008; Eerland, Engelen, \&Zwaan, 2013). Linguistic analysis furthermore suggests that direct speech, not indirect speech, is used in storytelling to make discourse more lively (Labov, 1972; Li, 1986; Mayes, 1990; Wierzbicka, 1974). Psychological research has yielded support for this view. Direct speech is perceived as more vivid and perceptually engaging than indirect speech (Yao, Belin, \& Scheepers, 2011, 2012; Yao \& Scheepers, 2011). For example, a context manipulation such that either a fast or a slow speaking protagonist was implied influenced reading times for direct but not indirect speech (Yao \& Scheepers, 2011). Reading times for direct but not indirect speech were also affected by whether a certain utterance was produced quickly or slowly (Stites, Luke, \& Christianson, 2013). Furthermore, people automatically activate 'audible speech'-like representations during silent reading (e.g., Zhou \& Christianson, 2016). Interestingly, reading direct speech resulted in more brain activation in voice-selective areas of the auditory cortex than reading indirect speech (Yao et al., 2011).

Together, these lines of evidence suggest that the use of direct speech invites a representation of the deliverance of the utterance: what exactly was said and how it was said.
More vivid information is more likely to be remembered than less vivid information (Reyes, Thompson, \& Bower, 1980). Therefore, Eerland et al. (2013) examined whether information in direct speech is more accessible than information in indirect speech. Participants read short stories with the last sentence always being in direct or indirect speech. After each story, they performed a probe recognition task where the probe was a noun mentioned in direct or indirect speech. Response times to the probe did not differ significantly between the speech type conditions, indicating that speech type did not affect the accessibility of information from the referential situation during comprehension.

This null finding could be interpreted as a demonstration of the lack of influence of speech type on item memory. Item memory can be defined as memory for the content, the gist, of an event and is thought to be part of episodic memory (Tulving, 1972). Not being able to remember what a story was about can therefore be seen as reflecting item memory difficulties. In addition to the content of an event, people could remember aspects of the context in which it took place. For example, one might recall the time and location of an event and how one came to know a particular fact (for a review, see Johnson, Hashtroudi, \& Lindsay, 1993). Memory for these types of information is known as source memory (e.g., McIntyre \& Craik, 1987; Schacter, Kaszniak, Kihlstrom, \& Valdiserri, 1991). Studies on item and source memory in patients (e.g., Janowsky, Shimamura, \& Squire, 1989; Schacter et al., 1991) and healthy adults (e.g., Glisky, Polster, Routhieaux, 1995; Senkfor \& Van Petten, 1998) demonstrate that item and source memory are functionally dissociable and can be located in different areas of the brain. According to the source monitoring framework, decision processes are performed during remembering to evaluate activated memory records and attribute them to specific sources, rather than those records being tagged during encoding. Could it be that the use of direct and indirect speech affects source memory rather than item memory? If so, this should occur during retrieval from long-term memory rather than during online processing.

Research in the field of sociolinguistics suggests that the use of indirect speech might enhance source memory. In indirect speech, what a protagonist said is conveyed indirectly. The narrator paraphrases what was said and does not pretend to use the speaker's original words. In direct speech, the impression is given that the protagonist's own words were used, although this is not necessarily the case (Norrick, 2007). For example, it is common to say: "I almost said to him, "You are a big liar!"' In this case, nothing was actually said. Nevertheless, because direct speech conveys a message as if it was spoken by a protagonist, it introduces a narrative shift from the reporting to the reported situation, whereas indirect speech remains anchored in the reporting situation. In direct speech, relative to the reporting context, the tense changes from past to present and grammatical person changes from third to first (see for a recent study Köder, Maier, \& Hendriks, 2015). As such, the deictic center (the time, location and perspective) shifts from the reporting 
situation to the reported situation (Coulmas, 1986). For example, in a direct speech case like 'He said to me: "You are a big liar"' readers are confronted with a shift in perspective and tense, whereas no shifts take place in the indirect case 'He said to me that I am a big liar'. Research on situation models has demonstrated that such narrative shifts tend to make information prior to the shift less available, leading, among other things, to weaker links in long term memory between statements separated by a narrative shift compared to statements not separated by a narrative shift (see Zwaan \& Radvansky, 1998 and Zwaan \& Rapp, 2006 for reviews). Given that direct speech entails a narrative shift (or multiple shifts) whereas indirect speech does not, one might predict-following the research on situation models-that the link between the name of the speaker and what was said is stronger in indirect speech, where the two are not separated by a narrative shift, than in direct speech, where the two are separated by a narrative shift. In other words, whereas direct speech may lead to better memory for exactly what was said (e.g., Eerland et al., 2013), the prediction here is that it leads to weaker memory of who said what.

The literature on source memory offers a related perspective. The strength of the link between the content and the source of the information is subject to a number of factors, such as time pressure and loss of attention during source monitoring. These factors prevent effective encoding of contextual information, making the person unable to remember from what source the information is obtained (Johnson, 1997; Johnson et al., 1993). Several studies examined whether people monitor source credibility in narrative and expository discourse comprehension (see Sparks \& Rapp, 2011; Strømsø, Bråten, Britt, \& Ferguson, 2013 for recent examples). The question we are interested in here is more basic. We are interested in the identity rather than the credibility of the source. Previous research on source identity found better source memory for stories with a first person narrator (e.g., "I came home and poured myself a Scotch") than a third person narrator (e.g., "He came home and poured himself a Scotch"; Graesser, Bowers, Olde, \& Pomeroy, 1999; Graesser, Millis, \& Zwaan, 1997). This finding is neutral with regard to the question whether speech type affects source memory as the use of direct and indirect speech does not depend on a specific narrator perspective.

Remembering the source of information is crucial to the interpretation of the information content. For example, one would interpret a positive review of a new restaurant provided by a friend differently from a review by the owner of that restaurant. This is because people might infer motives from a source that will put the provided information in a different perspective. While it thus is important to pay attention to source information, people often fail to do so (see Britt \& Aglinskas, 2002; Wineburg, 1991 for examples in educational contexts).

In the context of a narrative, the source is the name of the speaker and what he/she says is the information. Narrative shifts are known to lead to increases in processing time (Zwaan \& Radvansky, 1998; Therriault, Rinck, \& Zwaan, 2006). Thus, a prediction that can be derived from source memory theory converges with a prediction from situation model theory: direct speech leads to weaker links between speaker and information than indirect speech.

One might argue that Experiments 2a and 2b of Eerland et al. (2013) already investigated the influence of speech type on source memory. Participants read sentences, adopted from Stites et al. (2013), in direct (e.g., John walked into the room and said energetically, "I finally found my car keys.") or indirect speech (e.g., John walked into the room and said energetically that he finally found his car keys). Then they performed a probe recognition task with the probe always being an adverb providing information about the way of speaking (e.g., energetically, casually, urgently). The goal of this experiment was to test the accessibility of information regarding a communicative situation for direct and indirect speech and to contrast this with the previously mentioned experiments on the accessibility of information about a referential situation. The combined data of Eerland et al.'s Experiments $2 \mathrm{a}$ and $2 \mathrm{~b}$ provided strong evidence for the conclusion that information about the way of speaking was more accessible after indirect than after direct speech. In retrospect, one might interpret this result as supportive of the notion that reading direct speech leads to a decline in source memory compared to reading indirect speech. After all, manipulations of the speaker's voice have been used in previous research to investigate source memory (e.g., Glisky et al., 1995; Senkfor \& Van Petten, 1998). Typically, studies on source memory for voice-specific information use auditorily presented stimuli that are completely different from the visually-presented stimuli in Eerland et al. (2013). The current study aims at a more straightforward investigation of source memory for direct and indirect speech. We will address the question whether speech type influences source memory for the speaker. Our hypothesis is that people have better source memory for information in indirect compared to direct speech.

Following best practices, we report how we determined our sample size, all data exclusions (if any), all manipulations, and all measures in the study (Simmons, Nelson, \& Simonsohn, 2012).

\section{Experiment 1}

We investigated source memory for statements that were reported in either direct or indirect speech. Given that, as discussed earlier, source memory effects occur during retrieval (rather than sources being tagged online), we used a memory task in which we presented participants with a story and later ask them to assign utterances taken from the story to one of the protagonists. We hypothesized that source memory would be better for participants who read the statements in indirect compared to direct speech.

\section{Method}

Participants We conducted a power analysis using G*Power (Erdfelder, Faul, \& Buchner, 1996) to estimate the sample size needed to detect a medium effect (Cohen's $f=.25$ ) in a between-subjects design with three groups. According to this power analysis, at least 159 valid 
participants were needed to obtain statistical power at the recommended .80 level (Cohen, 1988). We recruited 300 participants online through Amazon's Mechanical Turk (MTurk, http://www.mturk.com) of whom 299 completed the experiment. The sample had a mean age of 36.80 ( $S D=11.43$, range $=20-71,149$ females). All participants were residents of the USA and received $\$ 1.50$ for their participation, which required approximately 19 minutes. Three participants reported another language than English as their native language. With the exclusion of these participants, our sample included 296 native speakers of English.

Materials and procedure We created a story about Jake, Mike, Olivia, and Tammy, four colleagues who didn't know each other very well and decided to go to the pub after work (see Appendix S1). Each protagonist made 12 utterances, one about each of the ten topics they discussed and two about random topics All 48 (12 topics $\times 4$ protagonists) statements were presented in either direct or in indirect speech. In direct speech, the protagonist can either be mentioned before (e.g., Jane said "Let's go home") or after the reported speech (e.g., "Let's go home," Jane said). Rather than mixing those two options within the direct speech condition, we created two direct speech versions of the story: one in which the protagonist was always mentioned first (PF) and one in which the protagonist was always mentioned last (PL).

Participants were randomly assigned to one of the three speech conditions. Due to the length of the story, we presented the story in four parts. Reading times for each part were recorded. After participants read the whole story, they answered 24 multiple-choice questions regarding the statements that were mentioned (e.g., Who asked whether someone brought an umbrella?). Questions were presented one at a time and the answer options were always the names of the four protagonists. The 24 questions consisted of 2 questions per topic. The order of the topics was randomized as was the selection of the two (out of four) questions per topic. The answers given by the participants were recorded. The total number of correctly answered questions served as measure for source memory.

Next, participants filled out the Narrative Transportation Scale (Green \& Brock, 2000). This allowed for an exploratory analysis of the effect of speech on the degree of transportation into our narrative. ${ }^{1}$ The last question of the scale was repeated for all protagonists in the story. All 15 questions (e.g., While I was reading the narrative, I could easily picture the events in it taking place) had to be answered on a 7-point scale ( $1=$ not at all, $7=$ very much $)$ and were presented at once. We calculated a total score for narrative transportation as the sum of all 15 items, with a reversed score for items 2,5 , and 9.

Finally, participants were asked to make their best guess as to what the purpose of this task was. In addition, they indicated whether there were any noise or distractions while performing the task and what device they used to perform the task. Also, they stated their gender, age, level of education, native language, and the country of residence. The experiment was presented online in the
Qualtrics survey research suite (http://www.qualtrics. com).

\section{Results and Discussion}

We excluded data from 24 participants because they had reading times shorter than 0.05 seconds per word for at least one part of the story, which we took to mean that they had insufficiently processed that segment. Data from the remaining 272 participants were analyzed (see Table $\mathbf{1}$ ). We performed all analyses, both frequentist and Bayesian statistics analyses, in JASP (http://jasp-stats.org/).

Contrary to our prediction, we found no significant effect of speech type on source memory in a oneway ANOVA (see Table 2). Moreover, the Bayesian analysis shows that there is three times as much evidence for the null hypothesis than for the alternative hypothesis (see Table 3). There also was no effect of speech type on transportation (see Table 2). The Bayesian ANOVA shows that there was about four times as much evidence for the null hypothesis as for the alternative hypothesis (see Table 3).

Table 1: Proportion of Correct Answers Based on the Level of Protagonist Name and Gender, Degree of Transportation, and Number of Participants for Experiments 1-3.

\begin{tabular}{ccccc} 
& \multicolumn{2}{c}{ Source Memory } & & \\
\cline { 2 - 3 } & Name & Gender & Transportation & \\
\cline { 2 - 4 } & $\mathbf{M ( S D )}$ & $\boldsymbol{M}(\boldsymbol{S D})$ & $\boldsymbol{M}(\boldsymbol{S D})$ & $\mathbf{N}$ \\
\hline Experiment 1 & & & & \\
Indirect & $.61(.24)$ & $.83(.14)$ & $61.00(15.79)$ & 93 \\
Direct $-P F$ & $.54(.22)$ & $.77(.15)$ & $57.86(15.53)$ & 94 \\
Direct-PL & $.54(.22)$ & $.77(.13)$ & $56.44(14.55)$ & 85 \\
Experiment 2 & & & & \\
Indirect & $.58(.24)$ & $.79(.14)$ & $60.53(14.54)$ & 123 \\
Direct-PF & $.52(.23)$ & $.74(.16)$ & $55.07(15.99)$ & 105 \\
Experiment 3 & & & & \\
Indirect & $.62(.24)$ & $.83(.13)$ & $61.99(15.69)$ & 109 \\
Direct-PF & $.52(.22)$ & $.76(.14)$ & $60.04(14.82)$ & 109
\end{tabular}

Note. $\mathrm{PF}=$ protagonist mentioned first, $\mathrm{PL}=$ protagonist mentioned last.

Table 2: Summary of Oneway ANOVA Results for Experiment 1.

\begin{tabular}{lrrrrr} 
& \multicolumn{1}{c}{$\boldsymbol{S S}$} & $\boldsymbol{d} \boldsymbol{f}$ & $\boldsymbol{M S}$ & $\boldsymbol{F}$ & $\boldsymbol{p}$ \\
\hline SM Name & & & & & \\
$\quad$ Condition & 145.7 & 2 & 72.83 & 2.43 & 0.090 \\
$\begin{array}{l}\text { Residual } \\
\text { Transportation }\end{array}$ & 8049.8 & 269 & 29.92 & & \\
$\quad$ & & & & & \\
Condition & 981.9 & 2 & 490.0 & 2.09 & 0.126 \\
Residual & 63172.1 & 269 & 234.8 & &
\end{tabular}

Note. Type III sum of squares, $\mathrm{SM}=$ source memory. 
Table 3: Summary of Model Comparisons for Source Memory and Transportation Measures.

\begin{tabular}{cccccc} 
& $\mathbf{P}(\mathbf{M})$ & $\mathbf{P}(\mathbf{M} \mid$ data $)$ & $\boldsymbol{B F}_{\boldsymbol{M}}$ & $\boldsymbol{B F}_{\mathbf{1 0}}$ & Error \\
\hline SM Name & & & & & \\
Null model & 0.50 & 0.74 & 2.83 & 1.00 & \\
Condition & 0.50 & 0.26 & 0.35 & 0.35 & 0.02 \\
Transportation & & & & & \\
$\quad$ Null model & 0.50 & 0.80 & 3.87 & 1.00 & \\
Condition & 0.50 & 0.21 & 0.26 & 0.26 & 0.02
\end{tabular}

Note. $\mathrm{P}(\mathrm{M})=$ probability of a model, $\mathrm{P}(\mathrm{M} \mid$ data $)=$ probability of a model given the data, $B F_{M}=$ evidence null model/alternative model, $B F_{10}=$ evidence null hypothesis/evidence alternative hypothesis, Error $=$ Bayes error rate in percentages, $\mathrm{SM}=$ source memory.

Given that participants were not able to retrieve sufficient detailed source specifying information, we hypothesized that it might have been too difficult for them to remember exactly who made a certain statement due to the nature of our study. After all, all subjects had to go on was the protagonist's name. No further description was provided. However, the protagonist's gender could be inferred from the name. Perhaps participants did remember the protagonists' gender, even though they were unable to remember their names. To test this posteriori hypothesis, we calculated the number of correctly answered questions based on the gender of the protagonist. This score reflected source memory for the gender of the protagonist, which can be viewed as a more shallow measure of source memory. We found a significant difference between conditions for this measure of source memory, $F(2,269)=5.14, p=.006, \eta^{2}=0.04 ; B F_{10}=3.97$, which means that there is four times more evidence for the alternative hypothesis than for the null hypothesis. Bonferroni adjusted post hoc tests showed higher scores for source memory for participants in the indirect speech condition $(M=19.90, S D=3.31)$ than in the direct speech-PF $(M=18.55, S D=3.53)$, and the direct speech-PL conditions $(M=18.49, S D=3.23)$. There was no significant difference between both direct speech conditions. We performed Bayesian $t$-tests to examine these same patterns; in all test reported below, we used a Gauchy prior width of .701. The (one-sided) comparison between the indirect speech condition and the direct speech-PF condition produced $B F_{+0}=9.00$; similarly, the comparison of indirect speech with the direct speech-PL condition produced $B F_{+0}=14.11$. The (two-sided) comparison between the two direct speech conditions produced $B F_{10}=.16$. In other words, there is moderate to strong evidence that the indirect speech conditions lead to better source memory for the protagonist's gender than the direct speech condition and moderate evidence that the two direct speech conditions do not differ from each other in this regard, suggesting that the mentioning of the protagonist before or after the reported speech does not affect source memory.
Taken together, the results of Experiment 1 did not support our initial prediction that indirect speech leads to better memory for the identity of the speaker than direct speech. However, an exploratory analysis suggested that people were better at remembering whether a male or a female made a certain statement when they read this statement in indirect as compared to direct speech. There were no differences between conditions with respect to the level of transportation people experienced while reading the story that included the statements. The exploratory analysis suggested that speech was represented at the level of gender rather than the level of the individual.

In Experiment 2 we tried to replicate our findings from Experiment 1 but this time with the a priori hypothesis (De Groot, 1956/2014; Wagenmakers, Wetzels, Borsboom, van der Maas, \& Kievit, 2012) that indirect speech leads to better memory for the gender of the speaker than direct speech.

\section{Experiment 2}

Based on the results of Experiment 1, we hypothesized that indirect speech leads to stronger source representations at the gender level than direct speech. We tested this a priori hypothesis in Experiment 2. This experiment is in essence a replication of Experiment 1 with one change to the materials. All the statements uttered by a female protagonist were now uttered by a male protagonist and vice versa. This produced a counterbalancing of the links between gender and statements across Experiments 1 and 2. If the results of Experiment 1 were somehow due to these links, then the results would show a different pattern in Experiment 2. We did not expect to find effects of speech type on source representations on the individual level or on the degree of transportation. Because we found no effect of the positioning of the speaker relative to the reported speech in two direct speech conditions in Experiment 1, we only compared the indirect speech condition and the direct speech-PF condition. We chose the direct speech-PF condition, because this condition was most similar to the indirect speech condition, with the name of the protagonist being mentioned before the content of the utterance.

\section{Method}

Participants Based on the effect size obtained in Experiment 1 (Cohen's $d=.39$ ), ${ }^{2}$ we conducted a power analysis in $G^{*}$ Power (Erdfelder et al., 1996) to estimate the sample size needed to detect an effect of speech on source memory. According to this power analysis, at least 102 valid participants per condition were needed to obtain statistical power at the recommended .80 level (Cohen, 1988). We recruited 250 participants online through MTurk because we anticipated that the sample would include repeat participants (from Experiment 1) as well as non-native speakers of English and that we would have to remove data from participants that had implausibly short reading times. Two-hundred fifty-three participants completed the experiment. The sample had a mean age of 38.02 ( $S D=12.62$, range $=18-80,132$ females). All participants were residents of the USA and received $\$ 1.50$ 
for their participation, which required approximately 19 minutes. We excluded data from six participants because they reported another language than English as their native language. Also, we excluded data from seven participants because they had participated in Experiment 1. With the exclusion of these participants, our sample included 240 native speakers of English.

Materials and procedure Apart from the change we made to counterbalance the links between gender and statements across experiments, we used the same materials and procedure as in Experiment 1. As mentioned and explained before, we only included the indirect speech condition and the direct speech-PF condition in this experiment.

\section{Results and Discussion}

We excluded data from 12 participants due to reading times shorter than 0.05 seconds per word for at least one part of the story. Data from the remaining 228 participants were analyzed (see Table 1). We used two-tailed $t$-tests and one-sided Bayesian $t$-tests. At first sight, this may seem inconsistent but it is not. Two-tailed $p$ is testing only a point null hypothesis; one-sided $\mathrm{BF}$ compares the same point null to some alternative. Therefore, a point null is being tested in both scenarios. ${ }^{3}$

We found a significant effect for speech type on memory for the gender of a protagonist and no significant effect for speech type on memory for the protagonist's name (see Table 4). The Bayesian $t$-test shows there is moderate-to-strong evidence that speech type affects source memory at the level of protagonist gender. The evidence that it affects protagonistidentity memory is rather weak, with the evidence for the alternative hypothesis being only 1.3 times stronger than that for the null hypothesis (see Table 5). People were better at remembering the gender of the protagonist who made a certain statement after reading this statement in indirect compared to direct speech. These findings replicate those of Experiment 1. Unlike in Experiment 1, we found that speech type influenced transportation. People felt more transported in the indirect speech than the direct speech condition (see Table 4). The Bayesian analysis shows that there is four times as much evidence for the alternative hypothesis than for the null hypothesis.

To examine the aggregate effects of speech type, we performed random-effect meta-analyses on

Table 4: Summary of $t$-Test Results for Experiments 2 and 3.

\begin{tabular}{lcccr} 
& $\boldsymbol{t}$ & $\boldsymbol{d} \boldsymbol{f}$ & $\boldsymbol{p}$ & Cohen's $\boldsymbol{d}$ \\
\hline Experiment 2 & & & & \\
$\quad$ Name & 1.88 & 226 & .062 & - \\
Gender & 2.75 & 226 & .007 & 0.33 \\
$\quad$ Transportation & 2.70 & 226 & .007 & 0.36
\end{tabular}

Experiment 3

$\begin{array}{lrrrr}\text { Name } & 3.27 & 216 & .001 & 0.43 \\ \text { Gender } & 4.10 & 216 & <.001 & 0.52 \\ \text { Transportation } & 0.95 & 216 & .346 & -\end{array}$

Table 5: Summary of Bayesian $t$-Test Results for Experiments 2 and 3.

\begin{tabular}{lrrr} 
& $\boldsymbol{B F}_{+\mathbf{0}}$ & $\boldsymbol{B F}_{\mathbf{1 0}}$ & Error \\
\hline Experiment 2 & & & \\
$\quad$ Name & - & 0.76 & $\sim 6.02 \mathrm{e}-6$ \\
$\quad$ Gender & 9.72 & - & $\sim 2.37 \mathrm{e}-9$ \\
$\quad$ Transportation & - & 4.35 & $\sim 2.83 \mathrm{e}-9$ \\
Experiment 3 & & & \\
$\quad$ Name & 41.54 & - & $\sim 2.87 \mathrm{e}-10$ \\
$\quad$ Gender & 652.50 & - & $\sim 6.27 \mathrm{e}-11$ \\
$\quad$ Transportation & - & 0.23 & $\sim 1.16 \mathrm{e}-5$
\end{tabular}

Note. $B F_{+0}=$ evidence alternative hypothesis indirect $>$ direct/evidence null hypothesis, $B F_{10}=$ evidence null hypothesis/evidence alternative hypothesis, Error = Bayes error rate in percentages.

the combined data of Experiments 1 and 2, using the Metafor package in R (Viechtbauer, 2010) for the dependent measures of both experiments. As expected, there was a significant meta-analytic effect of speech type on memory for the protagonist's gender $\left(\mathrm{M}_{\text {difference }}=.06, \mathrm{SE}=.02,95 \% \mathrm{CI}[0.03,0.08], p=.0047\right)$. However, we also found significant meta-analytic effects of speech type on memory for the protagonist's name $\left(\mathrm{M}_{\text {difference }}=.07, \mathrm{SE}=.02,95 \% \mathrm{CI}[0.02,0.11], p=.0002\right)$ and transportation $\left(\mathrm{M}_{\text {difference }}=4.44, \mathrm{SE}=1.52,95 \% \mathrm{CI}\right.$ $[1.45,7.42], p=.0036)$.

Although the meta-analysis showed effects of speech type on source memory at the level of the protagonist gender and identity, the separate analyses performed in Experiments 1 and 2 only showed an effect of speech type at the level of protagonist gender. This could be due to the fact that the characters were not individuated in the story. What differentiates the characters is mostly their name. Only the protagonist's gender can be inferred from their name. In Experiment 3 we tried to individuate the four protagonists by providing more information about them. A previous study suggests such additional information might enhance source memory (Geiselman \& Crawley, 1983). In this study, participants were instructed to remember as many spoken sentences, presented either in a male or female voice, as possible out of 24. Some participants received brief self-descriptions of the speakers' personal lives and were explicit told that "past research suggests that knowing something about the speakers in advance will help you to remember the sentences" (p. 16-17). Participants were better at remembering who had uttered a specific sentence if the speaker was made more meaningful to them. This is congruent with the fact that more meaningful information is remembered better (Bransford \& Johnson, 1972). We expected that providing additional information about our protagonists would lead to a speech (direct vs. indirect) effect on source memory at the level of the protagonist identity, in line with our original prediction. 


\section{Experiment 3}

We provided participants with additional information regarding the protagonists (their appearance, their home state, and their age) in the story. This was intended to make it easier to differentiate among the protagonists and to remember who said what. Based on this reasoning and on our previous results, we therefore expected source memory at the level of protagonist gender and at the level of the individual to be better in the indirect speech condition than in the direct speech condition. We did not expect to find differences between conditions for the degree of transportation. This experiment was preregistered on the Open Science Framework: https:// osf.io/frm6k/.

\begin{abstract}
Method
Participants Although we expected to find larger effects of speech type on source memory for this experiment than in our previous experiments, we wanted to include at least 102 valid participants per condition. As in Experiment 2, we recruited 250 participants online through MTurk because we anticipated that the sample would include repeat participants as well as non-native speakers of English and that we would have to remove data from participants who had implausibly short reading times. Two-hundred fifty-six participants completed the experiment. The sample had a mean age of 33.72 ( $S D=9.83$, range $=20-72,111$ females). All participants were residents of the USA and received $\$ 1.50$ for their participation, which required approximately 23 minutes. We excluded data from five participants because they reported another language than English as their native language. Also, we excluded data from three participants because they had participated in Experiment 1 or 2 . One participant participated twice in this experiment. We excluded all the data from this participant. With the exclusion of these participants, our sample included 246 native speakers of English.
\end{abstract}

Materials and procedure We used the same story as in Experiment 2 but we added information regarding the protagonists to the beginning of the story. For each protagonist we described their age, home state, and appearance (i.e., hair, eyes, clothing, and one other characteristic; see Appendix). For both speech conditions, we created two lists that differed with respect to the names we attached to a certain description. Half the participants read the original introduction to the protagonists and the other half of the participants read an introduction in which the names of the two female protagonists were switched and those of the two male protagonists. Apart from this introduction, the materials and procedure were the same as in Experiments 1 and 2.

\section{Results and Discussion}

We excluded data from 26 participants due to reading times shorter than 0.05 seconds per word for at least one part of the story and from two last-run participants in one of the conditions to equal both conditions regarding the number of participants. Data from the remaining 218 participants were analyzed (see Table 1).
As expected, we found a significant effect of speech type on source memory not only at the gender level but also at the individual level (see Table 4). Bayesian $t$-tests confirm these conclusions (see Table 5). There is very strong evidence for the prediction that indirect speech leads to better source memory for the speaker than direct speech. Thus, these analyses converge to show highly robust effects of speech type on memory for protagonist gender as well as protagonist identity. Source memory on both levels was better in the indirect than the direct speech condition. There was no significant effect of speech type on transportation (see Table 4). Bayesian analysis shows the evidence against this hypothesis is moderate (see Table 5).

\section{Experiment 4}

So far, we obtained convincing evidence that people have better source memory for information in indirect compared to direct speech. One could argue that perhaps the effects are not limited to source memory per se but that people have a better content memory overall for indirect compared to direct speech. To test this alternative explanation of our previous findings, we conducted an experiment in which we investigated the influence of speech type on both source and content memory. Whereas source memory is defined as remembering who made a particular statement, content memory is about remembering if a particular statement was made. Based on the results of Experiments 1-3, we expected source memory to be better in the indirect speech condition than in the direct speech condition. Statement detection (i.e., content memory) does not require participants to establish a link between content and source (i.e., the link that is influenced by speech type through narrative shifts). Therefore, we did not expect to find a difference between conditions for content memory. In other words, we predicted an interaction between speech type and memory type. This experiment was preregistered on the Open Science Framework: https://osf.io/957wh/.

\section{Method}

Participants According to a power analysis (see also https://osf.io/g5ehj/), we needed at least 60 valid participants per condition to reach a power of .80 for the interaction, conservatively assuming that source and content memory are correlated .3. We deemed it likely that the previous found effect of speech type on source memory would diminish because half of our participants answered the content questions first, which introduced a retention interval and likely produced interference. Also, we anticipated that the sample would include a large number of participants who had already participated in one of the previous experiments, non-native speakers of English, and that we would have to remove data from participants that had implausibly short reading times. Therefore, we recruited 250 participants online through MTurk, like in Experiments 2 and 3. Two-hundred and forty participants completed the experiment. The sample had a mean age of $34.76(S D=10.69$, range $=19-71,135$ females). All participants were residents of the USA and 
received $\$ 1.50$ for their participation, which required approximately 22 minutes. We excluded data from three participants because they reported another language than English as their native language. Also, we excluded data from 43 participants because they had participated in Experiments 1-3 or another experiment that used the same story. With the exclusion of these participants, our sample included 194 native speakers of English.

Materials and procedure We used the same story as in Experiment 3. Because our previous experiments did not show any effect of list (i.e., whether the combination of a particular protagonist with a certain statement/appearance influenced source memory), we did not include list as a factor in this experiment. This means that there were only two versions of the story. Participants were randomly assigned to either the direct speech condition or the indirect speech condition. As in all previous experiments, the story was presented in four parts and reading times were measured.

After participants read the story they were presented with two blocks of questions. One block consisted of 24 questions with respect to source memory. These were the same questions we used in all previous experiments. The task was also the same (i.e., participants had to indicate which of the four protagonists made a certain statement). The only difference is that we did not use a random selection of 24 out of the 48 questions (as we did in Experiments 1-3). Instead, every participant received the exact same 24 questions but in a random order. This procedure was necessary to prevent the source and content memory questions from asking about the same statement. The 24 source memory questions consisted of two out of four questions for all 12 topics that were discussed in the story, with six questions for each protagonist. ${ }^{4}$ Questions were presented one at a time. The answers given by the participants were recorded. The total number of correct answers served as measure for source memory.

The other block consisted of 24 statements. Half of the statements represented information that was mentioned in the story (e.g., One of the colleagues didn't think of bringing an umbrella from home), half of them did not (e.g., One of the colleagues asked the waiter for the menu). For each statement participants indicated whether the statement was congruent with the story (by selecting the 'yes' answer option) or not (by selecting the 'no' answer option). As with the source memory questions, statements were presented one at a time and in random order. The order in which the two blocks of questions appeared was randomized. The answers given by the participants were recorded. The total number of correctly detected statements served as measure for content memory.

The remaining part of the task was exactly the same as in our previous experiments. Participants were asked to make their best guess as to what the purpose of this task was. They indicated whether there were any noise or distractions while performing the task and what device they used to perform the task. Also, they stated their gender, age, level of education, native language, and the country where they live. The experiment was presented online in the Qualtrics survey research suite (http://www. qualtrics.com).

\section{Results and Discussion}

We excluded data from 16 participants due to reading times being shorter than 0.05 seconds per word for at least one part of the story. This resulted in unequal numbers of participants in the indirect $(n=80)$ and direct speech $(n=98)$ conditions, and in the source memory first $(n=95)$ and content memory first $(n=83)$ order conditions. Therefore, we removed data from 38 last-run participants to equal all conditions regarding the number or participants. Data from the remaining 140 participants were analyzed (see Table 6).

As expected, we found better source memory in the indirect than direct speech condition. We found no difference between conditions for content memory. So, speech type influenced source memory for the speaker but not content memory. This speech type (direct vs. indirect speech) $\times$ memory (source vs. content memory) interaction effect was significant, $F(1,136)=7.25, p=.008$, $\eta^{2}=.05$. Not relevant to our hypothesis, question order did not influence source memory but it did influence content memory, with better content memory when these questions were asked first. This order $\times$ memory (source vs. content memory) interaction effect was also significant, $F(1,136)=4.80, p=.03, \eta^{2}=.03$.

These results show that the effects of speech type on source memory we consistently found cannot be explained by better memory in general in the indirect speech condition compared to the direct speech condition. Bayesian analysis supports these conclusions. A Bayesian mixed ANOVA with the same design as the frequentist

Table 6: Proportion of Correct Answers for Source and Content Memory, and Number of Participants for Experiment 4.

\begin{tabular}{lccc} 
& \multicolumn{2}{c}{ Memory } & \\
\cline { 2 - 3 } & Source & Content & \\
\cline { 2 - 3 } & $\boldsymbol{M}(\boldsymbol{S D})$ & $\boldsymbol{M}(\boldsymbol{S D})$ & $\boldsymbol{N}$ \\
\hline SM first & & & \\
$\quad$ Indirect & $.53(.19)$ & $.81(.10)$ & 35 \\
$\quad$ Direct $-P F$ & $.47(.18)$ & $.84(.12)$ & 35 \\
$\quad$ Total & $.50(.19)$ & $.82(.11)$ & 70 \\
CM first & & & \\
$\quad$ Indirect & $.53(.21)$ & $.89(.11)$ & 35 \\
$\quad$ Direct-PF & $.45(.19)$ & $.86(.08)$ & 35 \\
$\quad$ Total & $.49(.20)$ & $.88(.10)$ & 70 \\
Total & & & \\
$\quad$ Indirect & $.53(.20)$ & $.85(.11)$ & 70 \\
$\quad$ Direct-PF & $.46(.18)$ & $.85(.10)$ & 70 \\
Total & $.49(.19)$ & $.85(.11)$ & 140
\end{tabular}

Note. $\mathrm{SM}=$ source memory, $\mathrm{PF}=$ protagonist mentioned first, $\mathrm{CM}=$ content memory. 
ANOVA just reported shows that the average of models including the speech type by memory interaction is four times more likely than the average of models not including that interaction $\left(B F_{\text {inclusion }}=4.33\right)$. A one-sided Bayesian independent samples $t$-test (scaling factor $=.70$ ) similarly shows more support for the hypothesis that indirect speech leads to better source memory for the speaker than direct speech, $B F_{+0}=4.12$. A two-sided Bayesian $t$-test (scaling factor $=.70$ ) shows that there is five times as much evidence for the null hypothesis of no speech effect on content memory than for an effect in either direction, $B F_{01}=5.45$. Taken together, these data support the prediction that indirect speech leads to better source memory for the speaker than direct speech, whereas speech type does not impact content memory.

\section{General discussion}

Our findings suggest that 1) direct and indirect speech quotations only influence source memory at the level of the individual when that individual is distinctive, and 2) the effects of speech type on source memory cannot be explained by a more general memory effect.

Experiments 1 and 2 showed no effect of direct and indirect speech on protagonist identity but on protagonist gender. These results suggest that people remember a general characteristic of the protagonists (i.e., gender) rather than a more distinctive one (i.e., a name) when no individuating information about each protagonist is provided. As expected, people were better at remembering the gender of a protagonist after indirect than direct speech. Our hypothesis that the protagonists were not distinctive enough to show an effect of speech type on source memory at the individual level was confirmed by the results of Experiments 3 and 4 . When additional information made the protagonists more distinctive and thus meaningful, we found an effect of direct and indirect speech on protagonist identity. Congruent with source memory theory and situation model theory, we found that people were better at remembering who said what for indirect than direct speech quotations. Experiment 4 also showed that the effects of speech type are specific to source memory, given that memory for the content of the story was not affected by the use of direct vs. indirect speech.

Our findings are congruent with those of Geiselman and Crawley (1983), who found that providing participants with additional personal information about a speaker enhanced source memory but did not influence sentence recognition. An important difference between Geiselman and Crawley (1983) and the current study is that they 1) explicitly instructed participants to use the speakers' personal information and 2) informed participants that this information was likely to help them remember the spoken utterances. We replicated these results without instructing or informing our participants (and by using written rather than spoken discourse). This suggests that people spontaneously use personal information about others to distinguish among protagonists and that this makes it easier to remember who said what. Our finding that speech type did not influence content memory is congruent with Eerland et al. (2013).
Despite that direct speech is perceived as more vivid (Stites et al., 2013; Yao et al., 2011, 2012; Yao \& Scheepers, 2011) and is used to make narratives more engaging (Labov, 1972; Li, 1986; Mayes, 1990; Wierzbicka, 1974), we found no clear evidence that people felt more transported when direct as compared to indirect speech was used. This could be due to the fact that the Narrative Transportation Scale (Green \& Brock, 2000) not only taps into visual imagery but also includes items regarding cognitive and emotional-affective aspects. Furthermore, there are various differences between our story and narratives that are written to entertain (e.g., length, writing style). It might be the case that our story is not susceptible to a measure of transportation that was developed for narratives.

This brings up a related issue. In all of our experiments, we used multiple items that were embedded in a single story. This allows for the investigation of speech type effects in discourse comprehension. We expect our results to replicate in experiments using different stories that are modelled after the same principles. Whether the effects of speech type on source memory would also apply to other genres needs to be investigated in future research.

There are some limitations to our findings. First, we only explored the effects of speech type on long-term memory (i.e., source memory and content memory). Future research could benefit from the use of online measures to investigate the effects of narrative shifts as they occur during online processing. Second, our stimulus text described a casual conversation among friends. It would be interesting to extend the investigation to conversations of greater consequence to the participants (e.g., police interrogations, political debates, social conflicts), in which it is more important to know who said what.

In summary, our results provide support for the idea that linguistic cues, such as the use of direct and indirect speech, shift the emphasis from a representation of the information content and form to a representation of the source.

\section{Data Accessibility Statement}

The materials and participant data of all experiments can be found on the Open Science Framework (https://osf.io/ rk548/).

\section{Additional File}

The additional file for this article can be found as follows:

- Appendix S1. Indirect speech version of the story used in all experiments. DOI: https://doi. org/10.1525/collabra.123.s1

\section{Notes}

${ }^{1}$ One could argue that the findings that direct speech is perceived as more vivid than indirect speech warrants the hypothesis that people feel more transported in both direct speech conditions than in the indirect speech condition. However, perceived vividness is just one out of three aspects of narrative transportation (Gerrig, 1993). Therefore, we had no clear expectations for the effect of speech type on transportation. 
2 Data of the indirect speech condition and the direct speech PF condition were used for this calculation.

${ }^{3}$ We thank Alexander Etz for explaining this logic to us.

${ }^{4}$ Due to an error in programming the experiment, the source memory task included only five statements from one of the protagonists, and seven from another protagonist. From both remaining protagonists we included six statements.

\section{Ethics and Consent}

The authors declare that at present and at the time of the study, the Utrecht of Linguistics OTS (UiL OTS) endorses the WMA Declaration of Helsinki - Ethical Principles for Medical Research Involving Human Subjects, as well as The Netherlands Code of Conduct for Scientific Practice issued in 2004 (revised in 2012) by the Association of Universities in the Netherlands (VSNU).

\section{Acknowledgements}

The study was inspired by a conversation with Ted Sanders.

\section{Funding Information}

This research was supported by a VENI grant from the Netherlands Organization for Scientific Research (NWO) [grant number 275-89-026] awarded to Anita Eerland.

\section{Competing Interests}

The authors have no competing interests to declare.

\section{Author Contributions}

- Contributed to conception and design: AE, RAZ

- Contributed to acquisition of data: AE, RAZ

- Contributed to analysis and interpretation of data: AE, RAZ

- Drafted and/or revised the article: AE, RAZ

- Approved the submitted version for publication: AE, RAZ

\section{Author Information}

Rolf A. Zwaan is a Senior Editor at Collabra: Psychology. He was not involved in the peer review of the article.

\section{References}

Bohan, J., Sanford, A. J., Cochrane, S., \& Sanford, A. J. S. (2008). Direct and indirect speech modulates depth of processing. Paper presented at the 14th Annual Conference on Architectures and Mechanisms for Language Processing (AMLAP). Cambridge, UK.

Bransford, J. D., Barclay, J. R., \& Franks, J. J. (1972). Sentence Memory: A constructive versus interpretive approach. Cognitive psychology, 3, 193-209. DOI: https://doi.org/10.1016/0010-0285(72)90003-5

Bransford, J. D., \& Johnson, M. K. (1972). Contextual prerequisites for understanding: Some investigations of comprehension and recall. Journal of Verbal Learning and Verbal Behavior, 11, 717-726. DOI: https://doi. org/10.1016/S0022-5371(72)80006-9

Britt, M. A., \& Aglinskas, C. (2002). Improving students' ability to identify and use source information.
Cognition and Instruction, 20, 485-522. DOI: https:// doi.org/10.1207/S1532690XCI2004_2

Clark, H. H. (2016). Depicting as a method of communication. Psychological Review, 123(3), 324-347. DOI: https://doi.org/10.1037/rev0000026

Clark, H. H., \& Gerrig, R. J. (1990). Quotations as demonstrations. Language, 66, 764-805. DOI: https:// doi.org/10.2307/414729

Cohen, J. (1988). Statistical power analysis for the behavioral sciences, (2nd ed.). Hillsdale, NJ: Lawrence Erlbaum Associates.

Coulmas, F. (1986). Direct and indirect speech. Berlin; New York; Amsterdam: Mouton, de Gruyter. DOI: https:// doi.org/10.1515/9783110871968

De Groot, A. D. (1956/2014). The meaning of "significance" for different types of research. Translated and annotated by Eric-Jan Wagenmakers, Denny Borsboom, Josine Verhagen, Rogier Kievit, Marjan Bakker, Angelique Cramer, Dora Matzke, Don Mellenbergh, and Han L. J. van der Maas. Acta Psychologica, 148, 188-194. DOI: https://doi. org/10.1016/j.actpsy.2014.02.001

Eerland, A., Engelen, J. A. A., \& Zwaan, R. A. (2013). The influence of direct and indirect speech on mental representations. PLOS ONE, 8(6), e65480. DOI: https:// doi.org/10.1371/journal.pone.0065480

Erdfelder, E., Faul, F., \& Buchner, A. (1996). GPOWER: A general power analysis program. Behavior Research Methods, Instruments, and Computers, 28, 1-11. DOI: https://doi.org/10.3758/BF03203630

Ferretti, T. R., Kutas, M., \& McRae, K. (2007). Verb aspect and the activation of event knowledge. Journal of Experimental Psychology: Learning, Memory, and Cognition, 33, 182-196. DOI: https://doi. org/10.1037/0278-7393.33.1.182

Geiselman, R. E., \& Crawley, J. M. (1983). Incidental processing of speaker characteristics: Voice as connotative information. Journal of Verbal Learning and Verbal Behavior, 22, 15-23. DOI: https://doi. org/10.1016/S0022-5371(83)80003-6

Gerrig, R. J. (1993). Experiencing narrative worlds. New Haven, CT: Yale University Press.

Glisky, E. L., Polster, M. R., \& Routhieaux, B. C. (1995). Double dissociation between item and source memory. Neuropsychology, 9, 229-235. DOI: https:// doi.org/10.1037/0894-4105.9.2.229

Graesser, A. C., Bowers, C., Olde, B., \& Pomeroy, V. (1999). Who said what? Source memory for narrator and character agents in literary short stories. Journal of Educational Psychology, 91, 284-300. DOI: https:// doi.org/10.1037/0022-0663.91.2.284

Graesser, A. C., Millis, K. K., \& Zwaan, R. A. (1997). Discourse comprehension. In: Spence, J. T., Darley, J. M., \& Foss, D. J. (Eds.), Annual Review of Psychology, 48. Palo Alto, CA: Annual Reviews Inc. DOI: https://doi. org/10.1146/annurev.psych.48.1.163

Green, M. C., \& Brock, T. C. (2000). The role of transportation in the persuasiveness of public narratives. Journal of Personality and Social 
Psychology, 79, 701-721. DOI: https://doi. org/10.1037//0022-3514.79.5.701

Huette, S., Winter, B., Matlock, T., Ardell, D. H., \& Spivey, M. (2014). Eye movements during listening reveal spontaneous grammatical processing. Frontiers in Psychology, 5, 1-7. DOI: https://doi.org/10.3389/ fpsyg.2014.00410

Janowsky, J. S., Shimamura, A. P., \& Squire, L. R. (1989). Source memory impairment in patients with frontal lobe lesions. Neuropsychologica, 27, 1043-1056. DOI: https://doi.org/10.1016/0028-3932(89)90184-X

Johnson, M. K. (1997). Source monitoring and memory distortion. Philosophical Transactions of the Royal Society B-Biological Sciences, 352(1362), 1733-1745. DOI: https://doi.org/10.1098/rstb.1997.0156

Johnson, M. K., Hashtroudi, S., \& Lindsay, S. D. (1993). Source monitoring. Psychological Bulletin, 114, 3-28. DOI: https://doi.org/10.1037/0033-2909.114.1.3

Johnson-Laird, P. N. (1983). Mental models. Cambridge, MA: Harvard University Press.

Kaup, B.(2001). Negation and its impact on the accessibility of text information. Memory and Cognition, 29(7), 960-967. DOI: https://doi.org/10.3758/BF03195758

Kaup, B., \& Zwaan, R. A. (2003). Effects of negation and situational presence on the accessibility of text information. Journal of Experimental Psychology: Learning, Memory, and Cognition, 29, 439-446. DOI: https://doi.org/10.1037/0278-7393.29.3.439

Köder, F., Maier, E., \& Hendriks, P. (2015). Perspective shift increases processing effort of pronouns: A comparison between direct and indirect speech. Language, Cognition, and Neuroscience, 30(8), 940-946. DOI: https://doi.org/10.1080/23273798.2 015.1047460

Labov, W. (1972). Language in the city: Studies in the Black English vernacular. Philadelphia: University of Pennsylvania Press.

Li, C. N. (1986). Direct speech and indirect speech: A functional study. In: Coulmas, F. (Ed.), Direct and indirect speech. Berlin; New York; Amsterdam: Mouton, de Gruyter. DOI: https://doi. org/10.1515/9783110871968.29

Lüdtke, J., Friedrich, C. K., De Filippis, M., \& Kaup, B. (2008). Event-related potential correlates of negation in a sentence-picture verification paradigm. Journal of Cognitive Neuroscience, 20(8), 1355-1370. DOI: https://doi.org/10.1162/jocn.2008.20093

Madden, C. J., \& Zwaan, R. A. (2003). How does verb aspect constrain event representation? Memory and Cognition, 31, 663-672. DOI: https://doi. org/10.3758/BF03196106

Magliano, J. P., \& Schleich, M. C. (2000). Verb aspect and situation models. Discourse Processes, 29, 83-112. DOI: https://doi.org/10.1207/S15326950dp2902_1

Mayes, P. (1990). Quotation in spoken English. Studies in Language, 14, 325-363. DOI: https://doi. org/10.1075/sl.14.2.04may

McIntyre, J. S., \& Craik, F. I. M. (1987). Age differences in memory for item and source information. Canadian
Journal of Psychology, 41(2), 175-192. DOI: https:// doi.org/10.1037/h0084154

Morrow, D. G., Greenspan, S. L., \& Bower, G. H. (1987). Accessibility and situation models in narrative comprehension. Journal of Memory and Language, 26, 165-187. DOI: https://doi. org/10.1016/0749-596X(87)90122-7

Norrick, N. R. (2007). Conversational storytelling. In: Herman, D. (Ed.), The Cambridge Companion to Narrative, 127-141. Cambridge: Cambridge University Press. DOI: https://doi.org/10.1017/ CCOL0521856965.009

Reyes, R. M., Thompson, W. C., \& Bower, G. H. (1980). Judgmental biases resulting from differing availabilities of arguments. Journal of Personality and Social Psychology, 39, 2-12. DOI: https://doi. org/10.1037/0022-3514.39.1.2

Schacter, D. L., Kaszniak, A. W., Kihlstrom, J. F., \& Valdiserri, M. (1991). The relation between source memory and aging. Psychology and Aging, 6(4), 559-568. DOI: https://doi. org/10.1037/0882-7974.6.4.559

Senkfor, A. J., \& Van Petten, C. (1998). Who said what? An event-related potential investigation of source and item memory. Journal of Experimental Psychology: Learning, Memory, and Cognition, 24, 1005-1025. DOI: https://doi.org/10.1037//0278-7393.24.4.1005

Sherrill, A. M., Eerland, A., Zwaan, R. A., \& Magliano, J. P. (2015). Understanding how grammatical aspect influences legal judgment. PLOS ONE, 1O(10): e0141181. DOI: https://doi.org/10.1371/journal. pone.0141181

Simmons, J. P., Nelson, L. D., \& Simonsohn, U. A. (2012, October 14). A 21 word solution. Retrieved from: http://ssrn.com/abstract=2160588.

Sparks, J. R., \& Rapp, D. N. (2011). Readers' reliance on source credibility in the service of comprehension. Journal of Experimental Psychology: Learning, Memory, and Cognition, 37, 230-247. DOI: https://doi. org/10.1037/a0021331

Stites, M. C., Luke, S. G., \& Christianson, K. (2013). The psychologist said quickly, "Dialogue descriptions modulate reading speed!". Memory and Cognition, 41, 137-151. DOI: https://doi.org/10.3758/ s13421-012-0248-7

Strømsø, H. I., Bråten, I., Britt, A. M., \& Ferguson, L. E. (2013). Spontaneous Sourcing Among Students Reading Multiple Documents. Cognition and Instruction, 31, 176-203. DOI: https://doi.org/10.108 0/07370008.2013.769994

Therriault, D. J., Rinck, M., \& Zwaan, R. A. (2006). Assessing the influence of dimensional focus during situation model construction. Memory \& Cognition, 34, 78-89. DOI: https://doi.org/10.3758/BF03193388

Tulving, E. (1972). Episodic and semantic memory. In: Tulving, E., \& Donaldson, W. (Eds.), Organization of memory, 381-403. New York: Academic Press.

Van Dijk, T. A., \& Kintsch, W. (1983). Strategies of discourse comprehension. New York: Academic Press. 
Viechtbauer, W. (2010). Conducting meta-analyses in $\mathrm{R}$ with the metafor package. Journal of Statistical Software, 36, 1-48. DOI: https://doi.org/10.18637/ jss.v036.i03

Wagenmakers, E., Wetzels, R., Borsboom, D., van der Maas, H. L. J., \& Kievit, R. A. (2012). An agenda for purely confirmatory research. Perspectives on Psychological Science, 7(6), 632-638. DOI: https://doi. org/10.1177/1745691612463078

Wierzbicka, A. (1974). The semantics of direct and indirect discourse. Paper in Linguistics, 7, 267307. DOI: https://doi.org/10.1080/08351817409 370375

Wineburg, S. S. (1991). Historical problem solving: A study of the cognitive processes used in the evaluation of documentary and pictorial evidence. Journal of Educational Psychology, 91, 1-11. DOI: https://doi. org/10.1037/0022-0663.83.1.73

Yao, B., Belin, P., \& Scheepers, C. (2011). Silent reading of direct versus indirect speech activates voice-selective areas in the auditory cortex. Journal of Cognitive Neuroscience, 23, 3146-3152. DOI: https://doi. org/10.1162/jocn_a_00022
Yao, B., Belin, P., \& Scheepers, C. (2012). Brain "talks over" boring quotes: Top-down activation of voiceselective areas while listening to monotonous direct speech quotations. NeuroImage, 60, 1832-1842. DOI: https://doi.org/10.1016/j.neuroimage.2012.01.111

Yao, B., \& Scheepers, C. (2011). Contextual modulation of reading rate for direct versus indirect speech quotations. Cognition, 121, 447-453. DOI: https://doi. org/10.1016/j.cognition.2011.08.007

Zhou, P., \& Christianson, K. (2016). I "hear" what you're "saying": Auditory perceptual simulation, reading speed, and reading comprehension. The Quarterly Journal of Experimental Psychology, 69, 972-995. DOI: https://doi.org/10.1080/17470218.2015.1018282

Zwaan, R. A., \& Radvansky, G. A. (1998). Situation models in language and memory. Psychological Bulletin, 123, 162-185. DOI: https://doi. org/10.1037/0033-2909.123.2.162

Zwaan, R. A., \& Rapp, D. N. (2006). Discourse comprehension. In: Gernsbacher, M. A., \& Traxler, M. J. (Eds.), Handbook of psycholinguistics, 725-764. San Diego, CA: Elsevier. DOI: https://doi.org/10.1016/ B978-012369374-7/50019-5

Editor Action Letter

The author(s) of this paper chose the Streamlined Review option, and the Editor's action letter is available at: http://doi. org/10.1525/collabra.123.pr

How to cite this article: Eerland, A., \& Zwaan, R. A. (2018). The Influence of Direct and Indirect Speech on Source Memory. Collabra: Psychology, 4(1): 5. DOl: https://doi.org/10.1525/collabra.123

Senior Editor: Simine Vazire

Editor: David Therriault

Submitted: 17 November 2017

Accepted: 28 December 2017

Published: 20 February 2018

Copyright: (c) 2018 The Author(s). This is an open-access article distributed under the terms of the Creative Commons Attribution 4.0 International License (CC-BY 4.0), which permits unrestricted use, distribution, and reproduction in any medium, provided the original author and source are credited. See http://creativecommons.org/licenses/by/4.0/. 